\title{
Masyaqqah dan Rukhshah Bagi Orang Sakit
}

\author{
Yush-Nawwir \\ Email: yush.nawwir@umi.ac.id \\ Dosen Tetap Universitas Muslim Indonesia
}

\begin{abstract}
Abstrak
Masyaqqah dan rukhshah adalah ibarat dua sisi mata uang yang berbeda namun tak dapat dipisahkan. Hubungan keduanya bisa disebut sebagai hubungan sebab akibat, artinya setiap ada masyaqqah dalam menunaikan kewajiban, maka harus ada rukhshah dalam melaksanakan kewajiban tersebut sehingga seorang mukallaf yang diberi kewajiban mampu menunaikan kewajibannya dalam bentuk yang lebih mudah dan longgar. Dengan cara seperti ini, maka seseorang mukallaf akan mengetahui bahwa sebuah kewajiban harus ditunaikan walau dalam kondisi apapun dan akan merasakan betapa rahmat Allah swt senantiasa menyertai manusia.
\end{abstract}

Kata kunci: masyaqqah, rukhsah, sakit.

\section{Pendahuluan}

Keberadaan manusia di muka bumi selaku hamba Allah mempunyai kewajiban yang harus ditunaikan. Karena adanya kewajiban tersebut, maka seorang hamba yang telah bertanggungjawab menunaikan kewajibannya di sebut mukallaf atau orang yang mempunyai beban atau tanggungjawab sedang beban kewajibannya disebut taklif .

Seluruh beban kewajiban atau taklif yang telah Allah swt bebankan kepada manusia adalah sesuatu yang mampu dipikul oleh manusia itu sendiri sebagaimana yang umum diketahui bahwa dalam al-Qur'an bahwa Allah tidak akan membebani seseorang kecuali orang tersebut mampu memikulnya.

Namun demikian, sebuah kewajiban kadangkala agak berat ditunaikan karena adanya luar yang memberatkan atau menyusahkan manusia melaksanakan kewajiban tersebut. Sesuatu yang memberatkan atau menyusahkan ini disebut masyaqqah.

Dengan adanya masyaqqah tersebut, maka manusia diberi kemudahan dan kelonggaran dalam menunaikan kewajiban tertentu dengan tetap mendapat pahala secara utuh dan sempurna. Segala bentuk kemudahan dan kelonggaran dalam menunaikan sebuah kewajiban karena adanya masyaqqah, disebut rukhshah.

Tulisan ini akan membahas tentang rukhsah yang telah digariskan oleh syariat dalam hubungannya dengan ibadah bagi orang sakit.

Berdasarkan pemaparan di atas, maka permasalahan yang akan diangkat adalah sebagai berikut:

Apa yang dimaksud masyaqqah dan rukhshah?

Bagaimana bentuk-bentuk rukhshah dalam ibadah bagi orang sakit?

\section{Pembahasan}

A. Pengertian Masyaqqah dan Rukhshah. 
Masyaqqah dan rukhshah adalah ibarat dua sisi mata uang yang berbeda namun tak dapat dipisahkan. Hubungan keduanya bisa disebut sebagai hubungan sebab akibat, artinya setiap ada masyaqqah/kesusahan dalam menunaikan kewajiban/taklif, maka harus ada rukhshah/kemudahan dalam melaksanakan kewajiban tersebut sehingga seorang mukallaf/yang diberi kewajiban mampu menunaikan kewajibannya/taklifnya dalam bentuk yang lebih mudah dan longgar. Dengan cara seperti ini, maka seseorang mukallaf akan merasakan betapa rahmat Allah swt senantiasa menyertai manusia.

Masyaqqah adalah suatu pernyataan atau ungkapan terhadap suatu masalah yang semestinya seseorang mampu menunaikannya namun karena adanya suatu hal tertentu sehingga mukallaf mengalami kesukaran dalam melaksanakannya ${ }^{1}$, atau dengan kata lain kesukaran yang menimpa mukallaf dalam melaksanakan taklif ilahi. $^{2}$

Dengan adanya kesukaran yang dihadapi dalam melaksanakan sebuah ibadah, maka muncullah yang namanya rukhsah atau kemudahan, sebagaimana kaedah hokum bahwa adanya masyaqqah mengharuskan adanya kemudahan. Jadi rukhsah adalah perubahan hukum dari hal yang sulit menjadi mudah karena adanya uzur yang dilandasi sebab hukum asal. ${ }^{3}$

\section{B. Bentuk-Bentuk Rukhshah dalam Ibadah bagi Orang Sakit}

1. Menghilangkan Haraj/Beban Hukum.

Allah swt. berfirman dalam QS al-Fath $\} / 48: 17$;

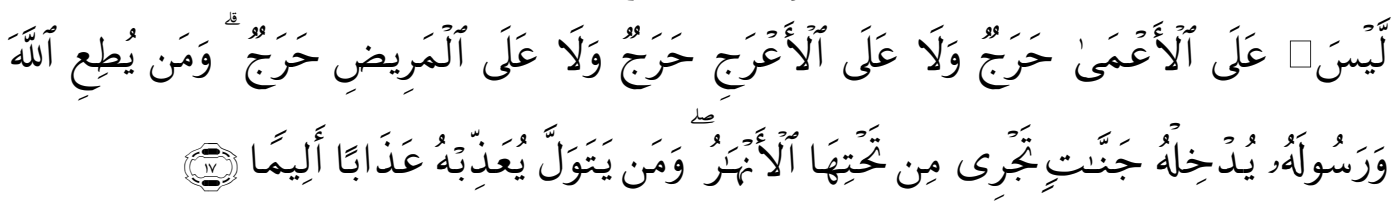

Terjemahnya:

Tidak ada dosa atas orang-orang yang buta, atas orang-orang yang pincang, dan atas orang-orang yang sakit (apabila tidak ikut berperang). Barangsiapa taat kepada Allah dan Rasul-Nya, Dia akan memasukkannya ke dalam surga yang mengalir di bawahnya sungai-sungai; tetapi barang siapa yang berpaling, Dia akan mengazab-Nya dengan azab yang pedih. ${ }^{4}$

Kata haraj terulang sebanyak 15 kali dalam al-Qur'an, semuanya dalam bentuk isim masdar, 13 ayat Makkiyah dan 2 ayat Madaniyah, tersebar dalam 8 surah. $^{5}$

${ }^{1}$ Al-Syatibi, al-Muwafaqat, juz II, (tt. 1990), 80

${ }^{2}$ Abd. Aziz Dahlan et al, Ensiklopedia Hukum Islam Indonesia jilid IV, Cet. I (Jakarta: PT Ikhiar Baru van Hoeve, 1996), 1149.

${ }^{3}$ Ismail Usman Zein, al-Mawahib al-Saniyah syarh Fawaid al-Bahiyah, (t.k, Dar alRasyid, t.th), h. 240.

${ }^{4}$ Kementerian Agama RI, Al-Qur 'an dan Terjemahnya, h. 513

${ }^{5}$ Muhammad Fu'ad ‘Abdul Baqi, al-Mu 'jam al-Mufahras li Alfaz al-Qur'an al-Karim, h. 
Penjelasan di atas menunjukkan bahwa penghilangan beban hukum tidak banyak terjadi dalam pelaksanaan ibadah. Kalaupun itu terjadi, hanya pada tataran individu saja, bukan pada suatu kelompok tertentu.

Menurut al-Ragib, haraj adalah pertemuan sesuatu hingga tampak celah sempit antara keduanya, ia juga bermakna kesempitan dan dosa. ${ }^{6}$ Dalam al-Qur'an, kata ini bermakna sempit/kesempitan (QS al-A'raf/17:2) dan bermakna dosa (QS al-Nur/24:61)

Munasabah ayat ini dengan ayat sebelumnya adalah bahwa ayat sebelumnya membicarakan tentang kewajiban berperang dan hubungannya dengan bai 'at al-ridwan, ketika seluruh sahabat yang hadir berjanji setia untuk berjuang bersama Rasulullah Saw dan barang siapa yang tidak ikut berjuang akan mendapat siksa dari Allah swt. Ayat ini kemudian memberi dispensasi bahwa boleh tidak ikut berperang dan tidak berdosa bagi orang buta, orang pincang dan orang sakit. Dua jenis sebelumnya yaitu orang buta dan pincang, secara logika keduanya dalam kondisi apapun, tidak akan dibebankan ikut perang karena cacat, namun sakit sebagai sesuatu yang kondisional dan temporal adalah penyebab seseorang diperbolehkan tidak ikut berperang, dan tidak termasuk orang yang membangkang jika tidak ikut berjuang bersama Rasulullah saw.

Ungkapan kata al-marid dalam ayat ini menunjukkan sakit yang dimaksud adalah sakit fisik sebagaimana yang telah dijelaskan sebelumnya.

2. Keringanan dalam Ibadah.

Keringanan dalam beribadah atau rukhsah ${ }^{7}$ adalah sebuah kemudahan atau keringanan dalam menjalankan suatu ibadah karena adanya uzur pada diri seorang hamba. Uzur adalah sesuatu yang menghalangi seorang hamba menunaikan kewajiban syar'i secara sempurna. Orang sakit adalah salah satu dari beberapa kelompok orang-orang yang mendapatkan keringanan tersebut dalam melaksanakan ibadah, meskipun pahalanya tetap diberikan secara sempurna sebagaimana ketika dilakukan pada masa sehat. Di antara rukhsah dalam hubungannya dengan orang sakit adalah:

a. Keringanan dalam Puasa Ramadhan

Allah berfirman dalam QS al-Baqarah/2:184-185;

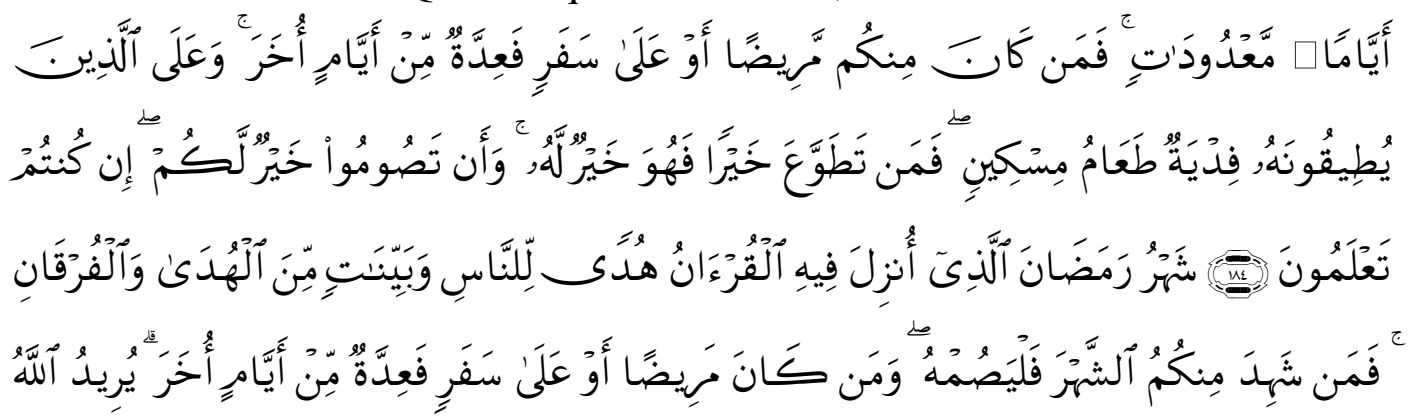

${ }^{6}$ Al-Ragib al-Asfahani, al-Mufradat fi Garib al-Qur'an, h. 112

${ }^{7}$ Rukhs\}ah menurut bahasa adalah kemudahan, menurut istilah syariat adalah identitas terhadap segala yang disyariatkan dalam kaitannya dengan kesusahan atau sesuatu yang dibolehkan karena uzur sedang ada dalil yang mengharamkannya atau apa yang didasarkan atas ketidakmampuan hamba. Lihat al-Jurjani, Kitab al-Ta'rifat, h. 115 


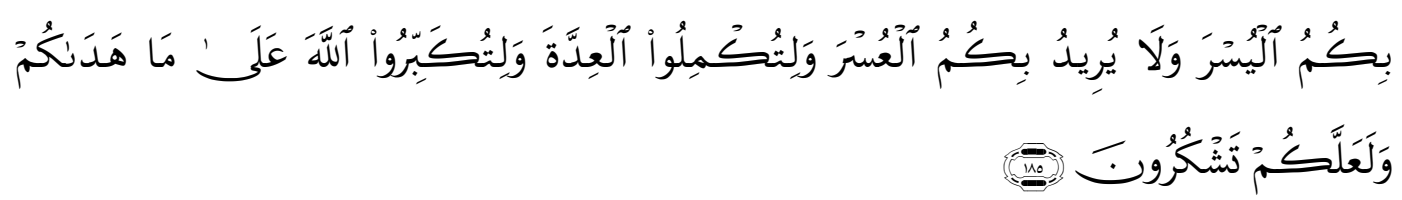

Terjemahnya:

(Yaitu) dalam beberapa hari tertentu. Maka barangsiapa diantara kamu ada yang sakit atau dalam perjalanan (lalu tidak berpuasa), maka (wajib mengganti) sebanyak hari (yang dia tidak berpuasa pada hari-hari yang lain. dan wajib bagi orang-orang yang berat menjalankannya, wajib membayar fidyah, yaitu memberi makan seorang miskin.Tetapi barangsiapa yang dengan kerelaan hati mengerjakan kebajikan, maka itu lebih baik baginya, dan puasamu lebih baik bagimu jika kamu mengetahui.

Bulan Ramadan, adalah (bulan) yang di dalamnya diturunkan Al-Qur'an, sebagai petunjuk bagi manusia dan penjelasan-penjelasan mengenai petunjuk itu dan pembeda (antara yang benar dan yang batil). Karena itu, barangsiapa di antara kamu ada di bulan itu, maka berpuasalah. Dan barangsiapa sakit atau dalam perjalanan (dia tidak berpuasa), maka (wajib menggantinya), sebanyak hari yang ditinggalkannya itu, pada hari-hari yang lain. Allah menghendaki kemudahan bagimu, dan tidak menghendaki kesukaran bagimu. Hendaklah kamu mencukupkan bilangannya dan mengagungkan Allah atas petunjuk-Nya yang diberikan kepadamu, agar kamu bersyukur. ${ }^{8}$

Kata al-shiyam terulang sebanyak 13 kali dalam al-Qur'an dengan 7 macam bentuk kata yang terdiri dari 2 kali kata kerja, semuanya kata kerja perintah, 11 kali kata benda dengan 9 kali isim mufrad, jamak muzakkar salim dan jamak muannas salim masing-masing 1 kali, 1 ayat Makkiyah dan 12 ayat Madaniyah, tersebar pada 6 surah. $^{9}$

Penjelasan di atas mengisyaratkan bahwa puasa adalah amalan individu yang dilakukan secara sendiri-sendiri oleh laki-laki dan perempuan. Dominasi ayat Madaniyah mengisyaratkan bahwa puasa ini semakin utama dilakukan pada era modern dalam menyokong pelaksanaan ajaran syari'ah. Puasa dapat juga dijadikan nazar sebagai lambang kekuatan aqidah.

Al-Shiyam terdiri dari huruf shad,waw dan mim menunjuk kepada menahan dan diam pada suatu tempat. ${ }^{10}$ Menurut al-Jurjani, puasa secara bahasa adalah menahan, menurut syariat adalah menahan makan, minum dan hubungan seks mulai dari subuh hingga magrib disertai dengan niat, ${ }^{11}$ juga berarti meninggalkan makan, minum, hubungan seks, dan kata-kata yang tak berguna. ${ }^{12}$ Menurut al-

${ }^{8}$ Kementerian Agama RI, Al-Qur 'an dan Terjemahnya, h. 28

${ }^{9}$ Muhammad Fu'ad 'Abdul Baqi, al-Mu 'jam al-Mufahras li Alfaz al-Qur'an al-Karim, h. 417

\footnotetext{
${ }^{10}$ Ahmad Ibn Faris, Mu 'jam Maqayis al-Lugah, jilid 3, h. 323

11 A Ali bin Muhammad Al-Jurjani, Kitab al-Ta 'rifat, h. 141

${ }^{12}$ Ibnu Manzur, Lisan al- 'Arab, jilid 4, h. 2529
} 
Ragib, Puasa menurut bahasa adalah menahan semua aktifitas, baik makan, bicara maupun berjalan, menurut syari'ah, menahannya seseorang mukallaf yang disertai niat sejak terbit fajar hingga terbenamnya matahari untuk makan minum, dan nikmat seks (baik onani ataupun hubungan suami istri), ada yang berpendapat, termasuk juga menahan bicara. ${ }^{13}$

Munasabah dengan ayat sebelumnya, bahwa pada ayat sebelumnya Allah menyinggung dua hal yang sangat berat, pertama adalah wajibnya qisas yaitu mengorbankan nyawa, yang merupakan beban berat, yakni seorang pembunuh harus menyerahkan dirinya untuk dibunuh juga, kedua adalah kewajiban wasiat yaitu mengeluarkan/memberikan harta yang merupakan kejujuran hati. Pada ayat ini Allah berbicara tentang kewajiban yang ketiga yaitu kewajiban puasa yang melelahkan dan melemahkan badan, memutuskan segala kebiasaan manusia di siang hari. ${ }^{14}$

Kata maridan pada ayat di atas bermakna bahwa sakit yang dimaksud adalah segala bentuk sakit fisik atau segala yang diidentifikasi sebagai sakit fisik, ini pendapat Ibnu Sirin, 'Atha' dan Bukhary, menurut jumhur; segala yang menimbulkan rasa sakit dan mengganggu serta dikhawatirkan bertambah sakitnya. Menurut Imam Malik, sakit yang menyebabkan adanya masyaqqah/kesusahan pada diri seseorang yang menyebabkan semakin bertambah sakit jika ia berpuasa, atau sakit keras yang bisa menambah sakitnya. Menurut al-Hasan dan al-Nakha'i, jika seseorang itu tidak mampu lagi puasa, ia harus berbuka. Menurut Imam Syafi' i, orang yang boleh berbuka apabila sakitnya itu akan membahayakan jika berpuasa. Kalau masih memungkinkan berpuasa dalam keadaan sakit, maka tidak perlu berbuka. Menurut Abu Hanifah, kalau dikhawatikan akan bertambah penyakitnya, tidak perlu berpuasa. ${ }^{15}$

Menurut al-Qurtubi, ada dua kondisi orang sakit dalam hubungannya dengan puasa yaitu kondisinya tersebut menyebabkan ia tidak mampu berpuasa, maka ia wajib tidak puasa; kedua, kondisinya mampu berpuasa tetapi berat baginya dan akan menimbulkan mudarat, maka kondisi ini lebih baik berbuka. ${ }^{16}$

Berbagai pendapat di atas dapat disimpulkan; pertama, menurut Ibnu Sirin, 'Ata' dan Bukhari, segala bentuk rasa sakit dan gangguan kesehatan, baik rendah, menengah atau tinggi, sebab Allah menurunkan rasa sakit pada seseorang agar orang tersebut dapat berbuka (tidak puasa). Dalam sebuah riwayat disebutkan bahwa Ibnu Sirin berbuka puasa karena jarinya terluka. Kedua, sakit yang kalau berpuasa akan bertambah parah, maka tidak perlu berpuasa. Ini pendapat Abu Hanifah, Malik dan Syafi' 'i. ${ }^{17}$

Penulis berpendapat, kehadiran penyakit dalam berbagai aspek dan bentuknya merupakan rahmat ilahi padi diri sesorang. Dalam hubungannya dengan

${ }^{13}$ Al-Ragib al-Asfahani, al-Mufradat fi Garib al-Qur'an,h. 291

${ }^{14}$ Muhammad al-Amin bin 'Abdullah al-Arumi, Hadaiq al-Ruh wa al-Raihan, juz 3, h. 148

${ }^{15} \mathrm{Abu}$ Hayyan al-Andalusi, al-Bahr al-Muhit, Juz (Cet. I, Beirut: Dar al-Kutub al'Ilmiyyah, 1993), h. 162

${ }^{16} \mathrm{Abu}$ 'Abdullah al-Qurtubi, al-Jami ‘ al-Ahkam al-Qur'an, juz 3, h. 127

${ }^{17}$ Al-Tahir Ibnu 'Asyur, al-Tahrir wa al-Tanwir, juz 2, h, 162 
puasa, seseorang boleh memilih antara puasa atau tidak, karena yang paling paham mudarat sebuah penyakit adalah orang menderita penyakit tersebut, atau berdasarkan petunjuk tabib yang berpengalaman.

3. Haji

Allah berfirman dalam QS al-Baqarah/2:196;
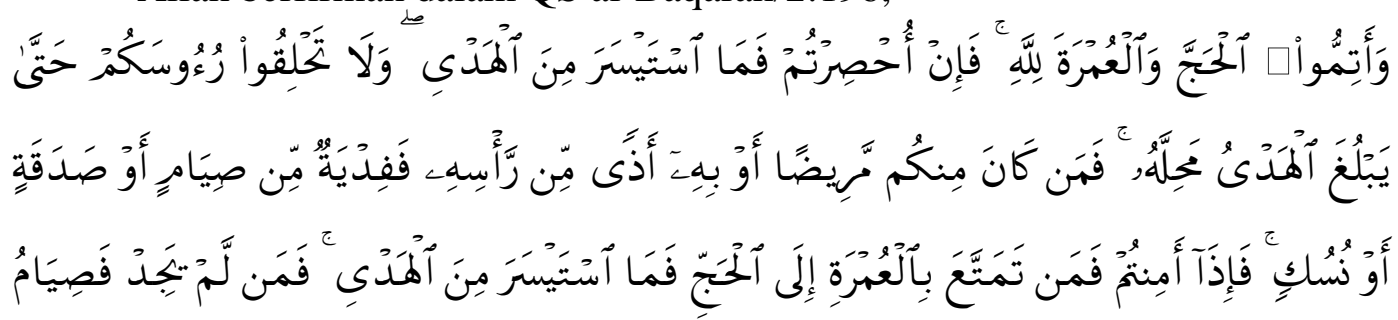

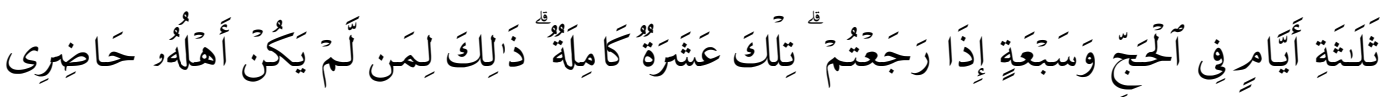

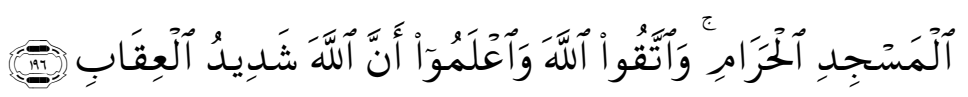

Terjemahnya:

Dan sempurnakanlah ibadah haji dan 'umrah karena Allah.Tetapi jika kamu terkepung (oleh musuh), Maka (sembelihlah) hadyu ${ }^{18}$ yang mudah didapat, dan jangan kamu mencukur kepalamu sebelum hadyusampai di tempat penyembelihannya.Jika ada di antara kamu yang sakit atau ada gangguan di kepalanya (lalu dia bercukur), maka dia wajib ber-fidyah, yaitu berpuasa, bersedekah atau berkurban. Apabila kamu dalam keadaan aman, maka barangsiapa mengerjakan 'umrah sebelum haji, dia (wajib menyembelih) hadyu yang mudah didapat. Tetapi jika dia tidak mendapatkannya, maka dia (wajib) berpuasa tiga hari dalam (musim) haji dan tujuh (hari) setelah kamu kembali. Itu seluruhnya sepuluh (hari). Demikian itu bagi orang yang keluarganya tidak ada (tinggal) di sekitar Masjidilharam. Bertakwalah kepada Allah dan ketahuilah bahwa Allah sangat keras hukuman-Nya. ${ }^{19}$

Kata al-Hajj terulang sebanyak 36 kali dalam Al-Qur'an terdiri dari 22 ayat Madaniyah dan 14 ayat Makkiyah, tersebar pada 10 surah. $^{20}$

Kata ini berasal dari huruf ha, jim dan jim dengan 4 (empat) makna dasar:

Menuju atau tujuan, dan dari sinilah makna haji

Tahun, makna ini bisa kembali ke makna haji yang dilakukan sekali setahun Tulang yang membulat di sekitar mata

\footnotetext{
${ }^{18} \mathrm{Hadyu}$ ialah hewan yang disembelih sebagai pengganti(dam) pekerjaan wajib haji yang ditinggalkan; atau sebagai denda karena melanggar hal-hal yang terlarang mengerjakannya di dalam ibadah haji. LihatKementerian Agama RI, Al-Qur 'an dan Terjemahnya, h. 30

${ }^{19}$ Kementerian Agama RI, Al-Qur 'an dan Terjemahnya, h. 30

${ }^{20}$ Muhammad Fu'ad 'Abdul Baqi, al-Mu 'jam al-Mufahras li Alfaz al-Qur'an al-Karim, h. 
Mundur dan menarik diri. ${ }^{21}$

Haji secara bahasa menuju ke sesuatu yang agung, secara syariat adalah sengaja menuju ke Baitullah dengan cara tertentu pada waktu tertentu dengan syarat-syarat tertentu. $^{22}$ Haji bermakna juga pergi untuk ziarah atau menuju Baitullah untuk melaksanakan manasik haji. ${ }^{23}$

Munasabah pada ayat sebelumnya adalah Allah swt., menyebut tentang puasa dan hukumnya lalu dilanjutkan pada ayat ini mengenai haji karena musim haji berada langsung sesudah puasa. ${ }^{24}$

Kalau pelaksanaan ibadah puasa membutuhkan pengorbanan mental dan spritual karena yang mengetahui tingkat kualitas puasa seseorang hanyalah pribadi orang yang bersangkutan, maka dalam pelaksanaan ibadah haji, dibutuhkan pengorbanan mental dan material karena beratnya pelaksanaan ibadah haji tersebut. Namun kedua ibadah ini sama-sama sangat rentan dimasuki hal-hal yang dapat merusak ibadah yaitu riya.

Sebab turunnya ayat ini berkaitan dengan $\mathrm{Ka}^{\text {' }} \mathrm{ab}$ bin 'Ajrah pergi menemui Rasulullah saw, ketika itu kutunya berkeliaran hingga ke wajahnya, Beliau berkata; saya melihatmu sangat susah, apakah kamu tidak punya seekor kambing?

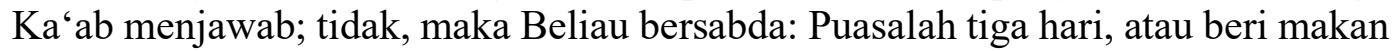
enam puluh orang miskin setengah $s_{\}} a^{\prime}$ setiap orang, kemudian cukur rambutmu. $\mathrm{Ka}$ 'ab mengatakan bahwa ayat ini turun secara khusus tapi berlaku untuk semua. ${ }^{25}$ Peristiwa ini dapat dijadikan landasan tentang pemberian rukhsah terhadap jamaah haji yang ditimpa masyaqqah/kesusahan ketika menunaikan ibadah haji.

Pengertian al-marad pada ayat di atas dalam kaitannya dengan pelaksanaan ibadah haji, bahwa tidak boleh mencukur rambut/tahallul sebelum tiba masanya. Kalimat fa man kaana minkum mariidan maka siapa saja di antara kalian yang sakit, bermakna jangan kalian mencukur rambut pada saat ihram kecuali terpaksa karena sakit atau ada sesuatu penyakit seperti banyak kutu di kepala atau flu, atau dengan kata lain siapa saja di antara kalian orang-orang yang sedang berihram ditimpa penyakit pada tubuhnya yang harus diobati dan menggunakan wewangian dan pakaian atau ada luka atau sesuatu yang dikhawatirkan akan menyebabkan timbulnya penyakit. ${ }^{26}$

4. Shalat

Allah berfirman dalam QS al-Nisa'/4:43;

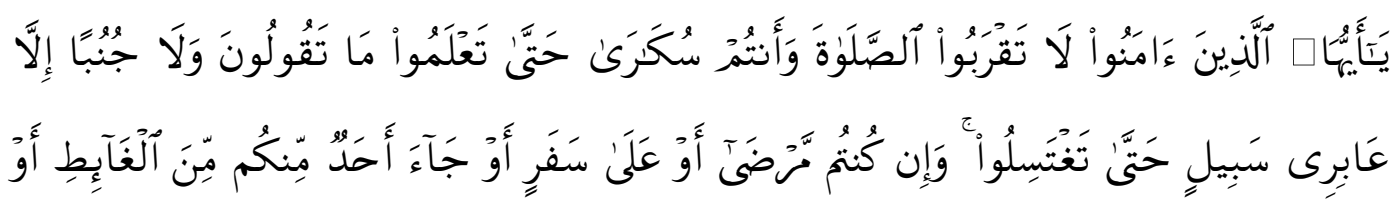

\footnotetext{
${ }^{21}$ Ahmad Ibn Faris, Mu ‘jam Maqayis al-Lugah, jilid 2, h. 29-31

22،Ali bin Muhammad al-Jurjani, Kitab al-Ta 'rifat, h. 85-86

${ }^{23}$ Al-Ragib al-Asfahani, Mufradat Alfaz al-Qur'an,h. 107

${ }^{24}$ Muhammad al-Amin bin 'Abdullah al-Arumi, Hadaiq al-Ruh wa al-Raihan, juz 3, h. 198

${ }^{25}$ Jalal al-Din al-Suyuti, Lubab al-Nuqul fi Asbab al-Nuzul, h. 36

${ }^{26}$ Muhammad al-Amin bin 'Abdullah al-Arumi, Hadaiq al-Ruh wa al-Raihan, juz 3, h. 205
} 


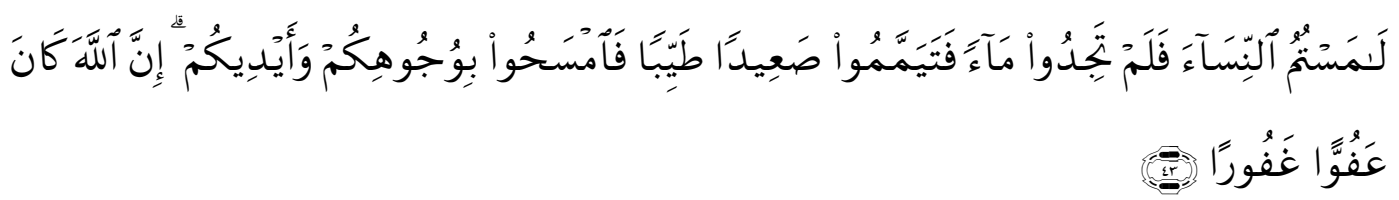

Terjemahnya:

Wahai orang yang beriman! janganlah kamu mendekati salat, ketika kamu dalam keadaan mabuk, sampai kamu sadar apa yang kamu ucapkan, dan jangan pula (kamu hampiri mesjid ketika kamu) dalam keadaan junub terkecuali sekedar melewati jalan saja, sebelum kamu mandi (mandi junub). Adapun jika kamu sakit atau sedang dalam perjalanan atau sehabis buang air atau kamu telah menyentuh perempuan, sedangkan kamu tidak mendapat air, maka bertayamumlah kamu dengan debu yang baik (suci); usaplah waahmu dan tanganmu dengan debu itu. Sungguh Allah Maha Pema'af, Maha Pengampun. ${ }^{27}$

Kata shalat dalam al-Qur'an dan devirasinya terulang 99 kali, 35 ayat Makkiyah dan 64 ayat Madaniyah. ${ }^{28}$

Secara bahasa kata shalat berasal dari huruf shad, lam dan huruf mu 'tal ya menunjuk kepada dua makna : 1) Api dan segala sesuatu yang panas, 2) Suatu jenis ibadah (shalat dan doa'), ${ }^{29}$ shalat juga berarti doa, secara syar'i adalah suatu perbuatan yang mempunyai rukun tertentu dengan zikir tertentu dan syarat tertentu dan waktu tertentu, juga berarti memohon kemulian dunia dan akhirat di sisi Rasulullah saw. ${ }^{30}$ Shalat juga berarti ruku' dan sujud, do'a dan istigfar dan rahmat Allah swt. ${ }^{31}$

Menurut al-Ragib, makna asalnya adalah menyalakan api, kemudian bermakna berkah, do'a dan pujian. Salat sebagai ibadah tertentu berasal dari makna do'a. Penamaan ini sama dengan penamaan sesuatu yang ada tercakup di dalamnya. Salat adalah ibadah yang dikerjakan sesuai syari'at walaupun ada sedikit perbedaan dalam gerakan tertentu sesuai dengan pendapat tertentu secara syar'i. ${ }^{32}$

Munasabah ayat sebelumnya adalah Allah memberitakan keadaan hari kiamat dan kondisi yang dialami orang kafir ketika itu ia tidak dapat menyembunyikan kekafirannya. Allah kemudian menjelaskan bahwa orang-orang yang selamat pada hari itu adalah orang-orang yang bersih hati dan anggota tubuhnya disertai dengan keimanan kepada Allah swt, dan ketaatan kepada Rasulullah saw. Pada ayat ini Allah menjelaskan etika dan tatacara bersuci dan beribadah serta berzikir agar mendapat keselamatan pada hari itu.

\footnotetext{
${ }^{27}$ Kementerian Agama RI, Al-Qur 'an dan Terjemahnya, h. 85

${ }^{28}$ Muhammad Fu'ad 'Abdul Baqi, al-Mu 'jam al-Mufahras li Alfaz al-Qur'an al-Karim, h. $412-414$

${ }^{29}$ Ahmad Ibn Faris, Mu jam Maqayis al-Lugah, jilid 3, h. 300

30‘Ali bin Muhammad Al-Jurjani, Kitab al-Ta 'rifat, h. 139

${ }^{31}$ Ibnu Manzur, Lisan al-'Arab, jilid 4, h. 2490

${ }^{32}$ Al-Ragib al-Asfahani, Mufradat Alfaz al-Qur'an, h. 285
} 
Sebab turunnya ayat ini adalah dari 'Ali ra. berkata; 'Abd. Rahman bin 'Auf mengundang kami pada sebuah jamuan makan. Kami makan dan minum hamar (pada waktu itu hamar belum dilarang) tidak lama kemudian efek hamar mulai terasa, dan tidak lama setelah itu waktu shalat masuk, mereka menyuruh saya jadi imam lalu saya membaca surah al-Kafirun yaitu wahai orang-orang kafir saya menyembah apa yang kalian sembah dan kami menyembah apa yang kalian sembah, maka turunlah ayat ini. ${ }^{33}$

Dalam hubungannya dengan rukhsah shalat, ada dua aspek yang memeroleh keringanan khusus bagi yang sakit, yaitu:

1). Tayammum.

Kata ini terulang hanya dua kali dalam al-Qur'an semuanya dalam bentuk kata yang sama yaitu tayammum, yaitu masing-masing pada QS al-Nisa'/4:43, alMaidah/5:6. Semuanya Madaniyah dan tersebar dalam dua surah. ${ }^{34}$

Ada dua pendapat mengenai asal kata tayammum ini, yang pertama berasal dari huruf alif, mim dan mim, artinya bermaksud dengan sesuatu. Jadi kata tayammamu sha iidan thayyiban artinya; bermaksud melakukan sesuatu dengan debu yang bersih. Kata ini kemudian populer dengan makna menyapu wajah dan kedua tangan. Makna ini dipelopori oleh al-Khalil ${ }^{35}$ dan Ibn Faris. ${ }^{36}$ Pendapat kedua bahwa kata ini berasal dari akar kata ya, mim dan mim yang bermakna melakukan sesuatu, sehingga tayammum untuk salat dimaknai mengusap wajah dan kedua tangan dengan debu/tanah, ${ }^{37}$ pendapat ini dipelopori oleh Ibn Manzur ${ }^{38}$ dan alRagib. ${ }^{39}$ Menurut istilah, tayammum adalah bermaksud melakukan sesuatu dengan debu bersih dan menggunakannya dengan cara yang khusus untuk menghilangkan hadas. $^{40}$

Kata marda pada ayat di atas bermakna penyakit fisik yaitu penyakit yang dikhawatirkan akan semakin parah apabila terkena air, misalnya penyakit-penyakit kulit, seperti luka, borok dan sebagainya. ${ }^{41}$ Bahkan ada yang berpendapat bahwa semua yang bisa diidentifikasi sebagai sakit, baik ringan maupun berat, semuanya diberi kelonggaran untuk tidak berwudu akan tetapi dengan tayammum. ${ }^{42}$

2). Melaksanakan Shalat.

${ }^{33}$ Jalal al-Din al-Suyut \}i, Lubab al-Nuqul fi Asbab al-Nuzul, h. 75-76

${ }^{34}$ Muhammad Fu'ad 'Abdul Baqi, al-Mu 'jam al-Mufahras li Alfaz al-Qur'an al-Karim, h.

${ }^{35}$ Al-Khalil Ibnu Ahmad al-Farahidi, Kitab al- 'Ain, Juz. 1, h. 89.

${ }^{36}$ Ahmad Ibn Faris, Mu 'jam Maqayis al-Lugah, jilid 1, h. 30

${ }^{37}$ Mujamma‘ al-Lugah al-‘Arabiyah, Mu 'jam al-Wasit, h. 1096

${ }^{38}$ Ibnu Manzur, Lisan al- 'Arab, jilid 55, h. 4966

${ }^{39}$ Al-Ragib al-Asfahani, al-Mufradat fi Garib al-Qur'an, h. 552

40، Ali bin Muhammad al-Syarif al-Jurjani, Kitab al-Ta'rifat, h. 75

${ }^{41}$ Muhammad al-Amin bin 'Abdullah al-Arumi, Hadaiq al-Ruh wa al-Raihan, juz 6, h. 97

${ }^{42}$ Abu Hayyan al-Andalusi, al-Bahr al-Muhit, Juz 3, h. 268 
Shalat adalah kewajiban setiap individu muslim mukallaf yang harus ditunaikan dalam keadaan apapun. Untuk itu, dalam hubungannya dengan kondisi dan kehidupan, misalnya sakit, seorang muslim tetap melaksanakan salat dengan cara:

Jika orang yang sakit mampu berdiri dengan memakai tongkat atau bersandar di dinding, maka dia harus berdiri. Hal ini berdasarkan hadis yang menyatakan bahwa ketika Rasulullah mulai tua dan agak gemuk, beliau meletakkan tiang di tempat salat beliau sebagai tempat bersandar. ${ }^{43}$

Jika tidak mampu berdiri, boleh salat dengan duduk, baring dan seterusnya. Akan tetapi harus diingat bahwa semua rukun salat tetap dilaksanakan seperti berdiri, ruku', sujud dan seterusnya, namun semuanya itu cukup dikerjakan dengan isyarat saja dengan tetap membaca bacaan salat sebagaimana biasanya.

Dalam salat duduk, seseorang rukuk dengan membungkukkan sedikit badan dan sujud dengan membungkukkan badan lebih rendah daripada rukuk.

Dalam salat sambil berbaring miring, semua gerakan salat dilakukan dengan isyarat kepala jika masih memungkinkan.

Dalam salat sambil berbaring telentang, semua gerakan salat dilakukan dengan isyarat, jika tidak mampu maka dengan hati.

\section{KESIMPULAN}

Dari pembahasan di atas, Penulis menarik beberapa kesimpulan yaitu:

Rukhsah pada dasarnya merupakan manifestasi kasih sayang Allah swt kepada hambaNya berupa kemudahan menjalankan ibadah bagi orang yang mempunyai uzur yang menyebabkan ia tidak mampu menunaikannya sebagaimana yang seharusnya.

Bentuk-bentuk kemudahan menjalankan ibadah bagi orang sakit menunjukkan bahwa ibadah adalah suatu keniscayaan yang harus ditunaikan dalam kondisi apapun, sedang kemudahan bukan berarti gugurnya sebuah kewajiban bagi seorang hamba.

\section{Daftar Pustaka}

Al-Syatibi, al-Muwafaqat, juz II, tt. 1990

Abd. Aziz Dahlan et al, Ensiklopedia Hukum Islam Indonesia jilid IV, Cet.

I Jakarta: PT Ikhiar Baru van Hoeve, 1996

Ismail Usman Zein, al-Mawahib al-Saniyah syarh Fawaid al-Bahiyah, t.k, Dar al-Rasyid, t.th

Kementerian Agama RI, Al-Qur 'an dan Terjemahnya,

Muhammad Fu'ad 'Abdul Baqi, al-Mu 'jam al-Mufahras li Alfaz al-Qur'an al-Karim, Beirut: Dar al-Fikr, t. th

Al-Ragib al-Asfahani, al-Mufradat fi Garib al-Qur'an, Beirut: Dar al-Fikr, t. th.

Ali bin Muhammad al-Jurjani, Kitab al-Ta'rifat, Beirut: Dar al-Fikr, t. th. Ahmad Ibn Faris, Mu 'jam Maqayis al-Lugah, jilid 3, Beirut: Dar al-Fikr, t. th.

\footnotetext{
${ }^{43}$ Sulaiman Abu Dawud al Sajastani, Sunan Abu Dawud, juz I, h. 408, nomor hadis 948.
} 
Ibnu Manzur, Lisan al- 'Arab, jilid 4, Beirut: Dar al-Fikr, t. th

Muhammad al-Amin bin 'Abdullah al-Arumi, Hadaiq al-Ruh wa al-Raihan, juz 3, Cairo: Dar al-Rasyidah, 1998

Abu Hayyan al-Andalusi, al-Bahr al-Muhit, Cet. I, Beirut: Dar al-Kutub al'Ilmiyyah, 1993

Abu 'Abdullah al-Qurtubi, al-Jami ' al-Ahkam al-Qur'an, juz 3, Beirut: Dar al-Fikr, t. th.

Al-Khalil Ibnu Ahmad al-Farahidi, Kitab al- 'Ain, Juz. 1, Beirut: Dar al-Fikr, t. th. 